\title{
ARTIGOS
}

\section{A ANÁLISE DE CONTEÚDO COMO UMA METODOLOGIA}

ROSANA MARIA MENDES •

ROSANA GIARETTA SGUERRA MISKULIN

\section{RESUMO}

Neste artigo expomos a análise de conteúdo como uma metodologia de análise de dados da pesquisa qualitativa em Educação. A metodologia torna-se parte fundamental de um trabalho acadêmico, dando à pesquisa características que determinam a qualidade deste. Assim, apresentamos os "matizes" como o cenário em que o trabalho foi realizado, o período e o ambiente em que ocorreu o Curso de Extensão (módulos I e II), a escolha dos softwares utilizados, os participantes, as entrevistas coletivas e a explicitação de como se fizeram a coleta de dados e os registros orais e escritos. Com esse material, como bricoleurs, artesãs cosendo seu patchwork, fomos construindo nossa investigação, realizada com um enfoque qualitativo, tendo os dados analisados a partir da Análise de Conteúdo proposta por Bardin (1977) e Franco (2008).

PESQUISA QUALITATIVA • ANÁLISE DE CONTEÚDO • EDUCAÇÃO • MATEMÁTICA

\section{CONTENT ANALYSIS AS A METHODOLOGY}

\section{ABSTRACT}

In this article we discuss content analysis as a method for analysing data of qualitative research in education. The method is a fundamental part of academic work, because it gives to the investigation some characteristics which are central to determine its quality. Thus, we present the "shades", such as the scenario in which the study was conducted, the period and the environment in which an extension course took place (modules I and II), the choice of the software employed, the participants, the press conferences and the explanation of how data collection and oral and written records were produced. Data analyses were based on content analysis proposed by Bardin (1977) and Franco (2008). With this material, like bricoleurs or artisans sewing their patchwork, we went about building our research. 


\section{L'ANALYSE DE CONTENU COMME MÉTHODOLOGIE}

RÉSUMÉ

Cet article présente l'analyse de contenu comme méthodologie de la recherche qualitative en Éducation. La méthodologie devient une part fondamentale du travail académique et accorde à la recherche des caractéristiques déterminantes de sa qualité. Les "nuances" sont présentées comme scénario dans lesquel le travail a été réalisé, à savoir, la période et l'environnement où le Cours d'Extension (modules I et II) a été réalisé, le choix des logiciels utilisés, les participants, les entretiens collectifs et l'explicitation de la modalité de réalisation de la collecte des données et des rapports oraux et écrits. A partir de ce matériel, comme des bricoleurs ou des artisans tissant leur patchwork, nous avons batit notre enquête avec une approche qualitative appuyée dans l'Analyse de Contenu proposée par Bardin (1977) et Franco (2008).

RECHERCHE QUALITATIVE • ANALYSE DE CONTENU • ÉDUCATION •

MATHÉMATIQUES

\section{EL ANÁLISIS DE CONTENIDO COMO UNA METODOLOGÍA}

RESUMEN

En este artículo exponemos el análisis de contenido como una metodología de análisis de datos de la investigación cualitativa en Educación. La metodología es parte fundamental de un trabajo académico, dándole a la investigación características que determinan su calidad. Así, presentamos los "matices" como el escenario en el que el trabajo se realizó, el periodo y el ambiente en que ocurrió el Curso de Extensión (módulos I y II), la elección de los softwares utilizados, los participantes, las entrevistas colectivas y la explicitación de cómo se llevó a cabo la recogida de datos y los registros orales y escritos. Con este material, como bricoleurs, artesanas cosiendo su patchwork, fuimos construyendo nuestra investigación, realizada con un enfoque cualitativo, y los datos se analizaron a partir del Análisis de Contenido propuesto por Bardin (1977) y Franco (2008). 
ESTE ARTIGO APRESENTAMOS A ANÁLISE DE CONTEÚDO COMO UMA METODOLOGIA DE análise de dados de uma pesquisa qualitativa em Educação Matemática. Para tanto, utilizaremos a metáfora de uma colcha de retalhos, em que, ao pegarmos os "pedaços de panos de vários matizes", como a questão de investigação e os objetivos, o referencial teórico adotado, a transparência dos procedimentos metodológicos para a constituição dos dados e os procedimentos de análise dos dados, como bricoleurs, como artesãs cosendo seu patchwork, construímos a investigação proposta.

Assim, expomos a metodologia de constituição dos dados de uma pesquisa de doutorado que buscou investigar a negociação de significado que pode ocorrer em um processo de formação do professor de Matemática em um grupo do Programa Institucional de Bolsas de Iniciação à Docência - Pibid - da Universidade Federal de Lavras UFLA - quando planejam, experimentam, vivenciam e refletem sobre a complexidade de se ensinar Matemática com a mediação da tecnologia (MENDES, 2013).

Recorrendo à nossa metáfora, a confecção de uma colcha de retalhos inicia-se com a escolha do retalho que comporá o "centro" do trabalho. No nosso caso, tal escolha foi a pesquisa qualitativa, tomando-se como referência os estudos de Denzin e Lincoln (2006), Bogdan e Biklen (1994), Chizzotti (1991) e Lüdke e André (1986), que apontam algumas características que configuram a pesquisa qualitativa. Um dos aspectos apontados por esses autores para ser considerado em uma pesquisa 
qualitativa refere-se ao fato de os dados que constituem a pesquisa serem predominantemente descritivos (LÜDKE; ANDRÉ, 1986), ou seja, “a descrição minudente, cuidadosa e atilada é muito importante; uma vez que deve captar o universo das percepções, das emoções e das interpretações dos informantes em seu contexto" (CHIZZOTTI, 1991, p. 82).

Dessa forma, na pesquisa qualitativa, foi registrada uma grande quantidade de dados descritivos e, como pesquisadores, ficamos intrigados sobre como poderíamos lidar com esse volume. São inúmeros "retalhos" que precisam ser unidos para responder à questão de investigação que nos propusemos e alcançar os objetivos. Qual é a melhor maneira de fazer isso? Quais seriam os melhores procedimentos metodológicos?

Segundo Bauer e Gaskell (2012), um dos primeiros problemas enfrentados por um investigador seria o de decidir qual método utilizar para um problema e como justificar os procedimentos metodológicos de constituição de dados e de análise.

Em nossa pesquisa, apresentada aqui como uma maneira de exemplificar a discussão sobre a utilização da análise de conteúdo como metodologia de análise de dados, de acordo com o objetivo proposto e buscando responder à questão de investigação, indagamos em muitos momentos sobre como iríamos decidir a respeito dos "retalhos"? A pesquisa seria confiável? Tais questões foram fundamentais para a tomada de decisão em relação aos procedimentos.

A confiabilidade, de acordo com Flick (2004, p. 343), “adquire sua relevância enquanto critério de avaliação da pesquisa qualitativa apenas em contraste com o pano de fundo de uma teoria específica sobre o assunto em estudo e que trate da utilização de métodos". No nosso caso, a teoria adotada foi a Comunidade de Prática (WENGER, 1998) e os instrumentos utilizados foram em forma de registros escritos, registros orais, entrevistas e diário de campo da pesquisadora, que nos possibilitaram perceber o caráter descritivo da pesquisa.

Flick (2004), discutindo sobre a confiabilidade, aponta que Kirk e Miller (1986 ${ }^{1}$ apud FLICK, 2004, p. 343) consideram a qualidade do registro e da documentação dos dados a base central para a avaliação da confiabilidade destes e das possíveis interpretações. Assim, uma segunda preocupação, depois de decidir sobre os procedimentos de constituição de dados, foi a forma como seria realizado o registro destes. Quais instrumentos de constituição de dados iríamos adotar?

\section{COMPONDO OS RETALHOS: A CONSTITUIÇÃO DOS DADOS DA PESQUISA}

Buscando ainda transparência e clareza nos procedimentos, uma vez que "são parte essencial na qualidade do trabalho de pesquisa" (BAUER; GASKELL, 2002, p. 483), apresentamos detalhadamente como os dados 
foram constituídos durante o Curso de Extensão (módulos I e II) realizado com os participantes do subprojeto da Matemática do Pibid/UFLA. Embora um dos resultados pretendidos por esse projeto, iniciado em 2010, fosse "promover a apropriação das Tecnologias da Informação e Comunicação nas práticas docentes” (MENDES, 2013, p. 74), até aquele momento não havia sido realizada nenhuma ação nesse sentido. Por essa razão, no primeiro semestre de 2011, conversamos com os participantes para saber qual seria a melhor estratégia para buscar atingir esse objetivo. Decidimos que um curso poderia ser uma boa opção.

O curso previa encontros presenciais e encontros não presenciais. Os primeiros, realizados no módulo II, ocorreriam em cada Grupo de Trabalho - GT. Os GTs eram compostos por seis licenciandos do curso de licenciatura em Matemática da Universidade Federal de Lavras, uma professora supervisora da escola participante do Pibid/Matemática e uma professora da universidade. Nos encontros não presenciais, em ambientes virtuais (módulos I e II), discutiríamos tanto as sequências de atividades elaboradas quanto alguns textos que julgamos importantes para reflexão sobre o processo de ensinar e aprender Matemática, mediado pela tecnologia. Os textos foram escolhidos pelas pesquisadoras. A dinâmica dos encontros foi baseada na reflexão, análise, discussão e compartilhamento de ideias e concepções sobre as leituras realizadas. $\mathrm{O}$ ambiente virtual de aprendizagem - AVA - utilizado foi o software Moodle - Modular Object-Oriented Dynamic Learning Environment. A UFLA mantém o AVA baseado no Moodle, que recebe o nome de Aprender/UFLA. Foi detalhado o ambiente, desde como era realizada a entrada no mesmo, até os recursos utilizados.

Os encontros presenciais foram audiogravados com gravadores digitais e utilizou-se um software gratuito de gravação e edição de som para auxiliar nas transcrições, o qual permitia identificar, isolar, arranjar seleções e ouvir várias vezes o mesmo momento. O software admitia que o som fosse editado e dispunha de diversos filtros que possibilitam depurá-lo, tendo uma contribuição importante em termos metodológicos.

Para nos orientar nas transcrições, estabelecemos alguns códigos baseados no trabalho de Koch (2003, p. 82-83) e apresentados no Quadro 1.

QUADRO 1

CÓDIGOS PARA A TRANSCRIÇÃO

\begin{tabular}{|l|l|}
\hline \multicolumn{1}{|c|}{ NOME } & \multicolumn{1}{c|}{ NOME FICTÍCIO DO PARTICIPANTE DA PESQUISA } \\
\hline Pesquisadora & Pesquisadora \\
\hline$/$ & Truncamento \\
\hline$\ldots$ & Pausa/silêncio \\
\hline() & Fala irreconhecível \\
\hline$[\ldots]$ & $\begin{array}{l}\text { Indicações de que a fala foi tomada ou interrompida/suprimida em } \\
\text { determinado (ou algum) ponto }\end{array}$ \\
\hline$(($ fala $))$ & Superposição, simultaneidade de vozes \\
\hline$:$. & Alongamento de vogal ou consoante \\
\hline- & Silabação \\
\hline$[$ minúsculas $]$ & Comentários descritos do transcritor/pesquisador \\
\hline
\end{tabular}

Fonte: Mendes (2013, p. 97-98). 
Depois de ouvidos várias vezes, os registros orais dos encontros presenciais foram transcritos. Entendemos que a transcrição não deva ser uma mera reprodução das gravações, mas uma busca por apresentar os tropeços, as frases interrompidas, as prolongadas, os suspiros, as exclamações, as contrariedades.

Para nos ajudar nessa tarefa, fizemos uso do diário de campo da pesquisadora, que se mostrou um importante instrumento de constituição de dados, pois nos auxiliou a relembrar detalhes dos encontros presenciais e das entrevistas que não podiam ser identificados somente nas falas, como as mensagens não verbais percebidas nas fisionomias e nos gestos.

A transcrição dos encontros presenciais (cerca de 50 horas) foi baseada nas partes relevantes da pesquisa, as quais tratavam do planejamento das atividades que seriam realizadas nas escolas e das reflexões e avaliação sobre como essas se processaram. Para elencar quais seriam essas partes, inspiradas em Hanna (2007), elaboramos um quadro para nos ajudar a perceber os excertos que iríamos transcrever. Para tanto, utilizamos alguns códigos para uma primeira seleção dessas partes dos dados da pesquisa (Quadro 2).

\section{QUADRO 2}

CÓDIGOS PARA OS ENCONTROS PRESENCIAIS

\begin{tabular}{|l|l|}
\hline \multicolumn{1}{|c|}{ CÓDIGO } & \\
\hline CP & Conversas paralelas \\
\hline CRO & Cronograma \\
\hline ESC & Discussões sobre questões práticas relativas à escola pública participante \\
\hline GRE & Discussões sobre a greve \\
\hline GT & Discussões sobre assuntos referentes ao GT \\
\hline MAT & Discussões sobre conteúdos matemáticos \\
\hline PED & Discussões sobre prática pedagógica \\
\hline POL & Discussões sobre políticas públicas \\
\hline PRE & Preparação da atividade \\
\hline PRO & Discussões sobre o projeto \\
\hline TEC & Discussões técnicas \\
\hline TEO & Discussões teóricas \\
\hline TIC & Discussões sobre a tecnologia \\
\hline
\end{tabular}

Fonte: Mendes (2013, p. 98).

Apresentamos, a seguir, um exemplo de uma parte de um quadro (Quadro 3) que fizemos para a transcrição dos encontros presenciais. Primeiramente, realçamos em amarelo as partes que provavelmente iríamos transcrever. Depois, voltamos a essas partes destacadas e ouvimos novamente. Escolhemos assim o conteúdo, de acordo com as categorias que seriam estabelecidas, sob o aporte metodológico de Bardin (1977) e Franco (2008). Esse conteúdo comporia o conjunto de dados. 
QUADRO 3

TRANSCRIÇÃO DOS ENCONTROS PRESENCIAIS - GT ESCOLA C - 02/05/2012 (INTEGRANTES: PROFESSORA DÓRIS, PESQUISADORAS ROSANA, DUDA, RAFAELLA, LETÍCIA, BEATRIZ, CLARA, APARECIDO)

\begin{tabular}{|l|l|l|}
\hline TEMPO & CÓDIGO & \multicolumn{1}{c|}{ ASSUNTO } \\
\hline 00:00:00 - 00:03:50 & MAT/PRE & $\begin{array}{l}\text { Heloisa comenta sobre as conversões de medida. } \\
\text { Simone questiona a professora sobre a atividade } \\
\text { proposta. Os outros bolsistas conversam sobre a } \\
\text { mesma. Heloisa faz ponderaçoses sobre a atividade e o } \\
\text { que pode ou não dar certo. }\end{array}$ \\
\hline 00:03:51- 00:14:59 & PRE & $\begin{array}{l}\text { Separando o material que seria utilizado na aula e } \\
\text { verificando como seria usado na atividade sobre } \\
\text { medida de comprimento. Simone faz alguns } \\
\text { questionamentos como seria melhor utilizar os } \\
\text { canudos. }\end{array}$ \\
\hline $00: 15: 00-00: 34: 39$ & PRE & $\begin{array}{l}\text { Débora e Simone discutindo mais de perto a respeito } \\
\text { da atividade sobre medidas de comprimento. } \\
\text { Planejaram que os alunos fizessem um registro escrito. }\end{array}$ \\
\hline
\end{tabular}

Fonte: Mendes (2013, p. 99).

Pensando em outros "retalhos" que comporiam nossa "colcha”, fizemos uma entrevista coletiva com os participantes do módulo I do curso, com o objetivo de fazer uma avaliação e possibilitando que os mesmos se reportassem às situações vivenciadas. Durante o módulo II foram realizadas duas entrevistas coletivas, uma no meio do curso e outra no final. Também foi feita uma entrevista com os alunos que participaram do módulo I e ficaram responsáveis pela moderação dos fóruns de discussão no Aprender/UFLA, visando a verificar suas percepções sobre a experiência. Todas as entrevistas foram transcritas integralmente.

Ao final do módulo II, solicitou-se aos participantes que escrevessem um registro reflexivo contendo suas reflexões sobre as leituras realizadas no curso (módulo II) e com as experiências nos GTs. Pedimos que eles comentassem sobre o impacto da sua participação no Pibid, quando iniciaram, o porquê de resolveram participar e se o GT já existia. Caso a participação fosse a um GT que já estava ocorrendo, solicitou-se que eles destacassem como foi participarem de um GT que já tinha uma dinâmica. Que dinâmica era essa? Quais foram os sentimentos e percepções dos participantes sobre esse GT? Se não, como foi perceberem a constituição desse GT? Como se estabeleceu a dinâmica do grupo? Pedimos ainda que fizessem uma reflexão sobre a experiência de cada um de participar do Pibid, como avaliavam essa participação e qual a avaliação sobre o Programa.

Assim, ainda pensando nas considerações de Flick (2004) sobre a confiabilidade na pesquisa qualitativa, explicamos a constituição dos dados de maneira detalhada. Decidimos de que forma esses dados seriam constituídos (a partir de um Curso de Extensão), quais seriam os instrumentos de coleta (registros escritos, registros orais, entrevistas e diário de campo da pesquisadora) e os procedimentos utilizados explicitando cada detalhe. Além disso, apresentamos, na metodologia da pesquisa, as escolas que participavam do Pibid/Matemática da UFLA naquela ocasião 
e os participantes do curso, destacando aspectos relacionados à sua formação acadêmica, aos seus conhecimentos sobre as tecnologias da informação e comunicação - TIC - e, no caso das professoras supervisoras e professoras da Universidade, às experiências profissionais. Utilizamos nomes fictícios, escolhidos pelos participantes, com o objetivo de preservar a identidade dos mesmos.

Com essa grande quantidade de dados descritivos em mãos (por volta de mil páginas impressas), precisávamos fazer a análise dos mesmos. Para tanto, teríamos que decidir como organizá-los e categorizá-los. Qual o melhor caminho a ser percorrido?

\section{A ANÁLISE DE CONTEÚDO: UM FIO PARA COMPOR A ANÁLISE DOS DADOS}

Após estes procedimentos de constituição de dados e recorrendo à nossa metáfora, da colcha de retalhos, os dados tornaram-se retalhos de nossa colcha e precisavam ser costurados para que o trabalho fosse concluído. Assim, a Análise de Conteúdo pode nos auxiliar com os dados que foram surgindo e que despontavam para uma possível resposta para a questão de investigação.

Nesse contexto, apresentamos, na Figura 1, o desenvolvimento da pesquisa baseado em Bardin (1977) e em Franco (2008).

\section{FIGURA 1}

DESENVOLVIMENTO DA PESQUISA

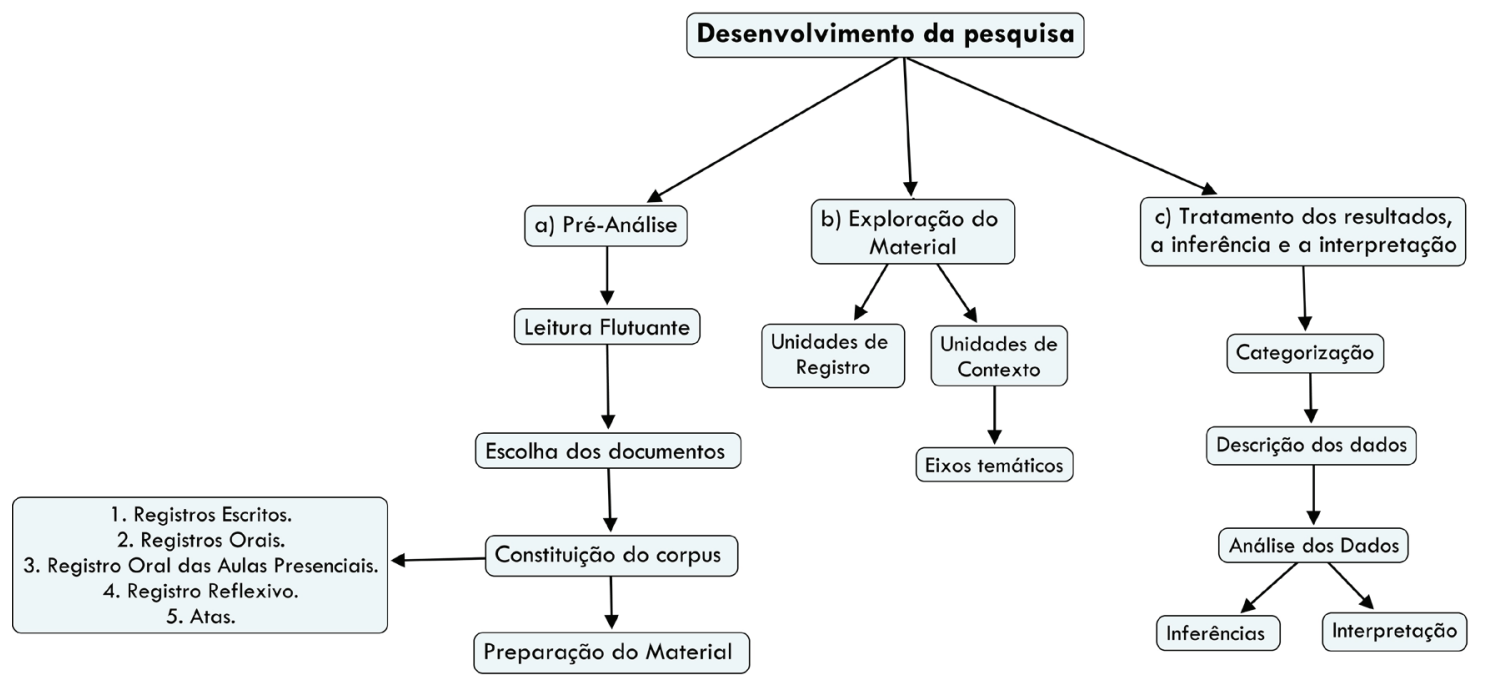

Fonte: Baseado em Bardin (1977, p. 102).

Com as transcrições das entrevistas coletivas e de partes dos encontros presenciais e o material do fórum de discussão em mãos, precisávamos organizá-los para a análise. Para isso, utilizamos a metodologia de Análise de Conteúdo que Bardin (1977, p. 42) define como 
[...] um conjunto de técnicas de análise das comunicações visando obter, por procedimentos sistemáticos e objectivos de descrição do conteúdo das mensagens, indicadores (quantitativos ou não) que permitam a inferência de conhecimentos relativos às condições de produção/recepção (variáveis inferidas) destas mensagens.

Para Franco (2008, p. 12), a mensagem pode ser "verbal (oral ou escrita), gestual, silenciosa, figurativa, documental ou diretamente provocada”. Em nossa pesquisa tivemos várias mensagens que foram sendo geradas durante o processo: aquelas dos registros escritos e orais, das falas realizadas durante os encontros presenciais, as mensagens silenciosas que fomos percebendo inclusive nos fóruns de discussão e as gestuais que percebemos durante os encontros presenciais ou as entrevistas coletivas e que foram registradas no diário de campo da pesquisadora.

Tínhamos em mente uma preocupação para não fazermos, conforme aponta Bardin (1977), uma “compreensão espontânea” dos dados que estavam em nossas mãos. A preocupação era ter uma atitude de "vigilância crítica” diante dos dados e, por essa razão, buscamos, por meio das inferências, atribuir-lhes significados.

Passamos pelas fases apontadas por Bardin (1977) e Franco (2008) e apresentadas a seguir.

\section{PRÉ-ANÁLISE}

Trata-se de uma fase de organização dos dados com o objetivo de constituir o corpus da pesquisa. "O corpus é o conjunto dos documentos tidos em conta para serem submetidos aos procedimentos analíticos” (BARDIN, 1977, p. 96).

Compor nosso corpus se mostrou uma tarefa bastante difícil, que implicou escolhas para a elaboração de um plano de análise. Tínhamos em mãos mais de mil páginas resultantes dos instrumentos de coleta de dados. O que fazer com todo esse material? Quais opções tínhamos? Quais implicações dessas escolhas para a pesquisa? Essas questões começaram a nos incomodar.

Fizemos a leitura flutuante, ou seja, estabelecemos um contato com os dados e buscamos uma primeira percepção das mensagens neles contidas, deixando-nos "invadir por impressões, representações, emoções, conhecimentos e expectativas” (FRANCO, 2008, p. 52).

Retomamos a questão da investigação e o objetivo proposto e passamos então para a escolha dos documentos. Como escolher esses documentos que iriam compor nosso corpus? Esses seriam suficientes para nos ajudar a inferir respostas à nossa questão e alcançar nosso objetivo?

Para nos auxiliar com esses questionamentos e em nossas angústias, uma vez que estávamos tentando ultrapassar a “compreensão 
instantânea”, recorremos às regras apresentadas por Bardin (1977), ainda na pré-análise da pesquisa:

- regra da exaustividade - "uma vez definido o campo do corpus [...] é preciso terem-se em conta todos os elementos desse corpus" (BARDIN, 1977, p. 97). Tínhamos os registros orais e escritos, entrevistas e questionários para a caracterização dos participantes e, para assegurar que iríamos contemplar essa regra, sentimos necessidade de retornar ao grupo/comunidade, com novos questionamentos (nos fóruns de discussão) para que esse corpus ficasse mais consistente;

- regra da representatividade - "A análise pode efectuar-se numa amostra desde que o material a isso se preste. A amostragem diz-se rigorosa se a amostra for uma parte representativa do universo inicial” (BARDIN, 1977, p. 97). No nosso caso, não recorremos a uma amostragem por não considerarmos que fosse necessário, pois trata-se de uma pesquisa qualitativa e nosso universo era possível de ser analisado em sua totalidade;

- regra da homogeneidade - “os documentos retidos devem ser homogêneos, quer dizer, devem obedecer a critérios precisos de escolha e não representar demasiada singularidade fora destes critérios de escolha” (BARDIN, 1977, p. 98). Entendemos que nossos documentos corresponderam a essa regra. Os questionamentos e inferências dos fóruns e das entrevistas foram os mesmos para todos os participantes;

- regra de pertinência - "os documentos retidos devem ser adequados, enquanto fonte de informação, de modo a corresponderem ao objetivo que suscita a análise” (BARDIN, 1977, p. 98). Essa regra está intimamente ligada àquela da homogeneidade. Entendemos que, em nossa pesquisa, os documentos foram adequados ao objetivo e questão de investigação da pesquisa, conforme será explicitado na análise de dados da pesquisa.

Sintetizamos, no Quadro 4, os instrumentos que compuseram nosso corpus da pesquisa. 


\begin{tabular}{|c|c|c|c|}
\hline INSTRUMENTOS & MÓDULOS & CÓDIGO & DESCRIÇÃO \\
\hline Registro escrito & I e II & PARTICIPANTE, r.e. - fórum - data & $\begin{array}{l}\text { Recolhido nos Fóruns de Discussão do } \\
\text { Aprender/UFLA. Indicamos o nome do } \\
\text { participante com letras maiúsculas, o } \\
\text { código - r.e. -, o fórum e a data em que foi } \\
\text { postada a mensagem. }\end{array}$ \\
\hline Registro oral & I e II & PARTICIPANTE, r.o. - data & $\begin{array}{l}\text { Recolhido a partir das entrevistas coletivas } \\
\text { realizadas com os participantes do curso } \\
\text { nos dois módulos. Foram realizadas } \\
\text { três entrevistas. Indicamos o nome do } \\
\text { participante com letras maiúsculas, o } \\
\text { código - r.o. - e a data em que foi realizada } \\
\text { a entrevista. }\end{array}$ \\
\hline $\begin{array}{l}\text { Registro oral } \\
\text { dos encontros } \\
\text { presenciais }\end{array}$ & II & $\begin{array}{l}\text { PARTICIPANTE, r.p. - GT Escola } \\
\text { - data }\end{array}$ & $\begin{array}{l}\text { Recolhido a partir das gravações realizadas } \\
\text { com os participantes do curso nos GT } \\
\text { de cada escola. Indicamos o nome do } \\
\text { participante com letras maiúsculas, o código } \\
\text { - r.p. -, o GT Escola (indicado por A, C ou D) e } \\
\text { a data em que foi realizada a aula presencial. }\end{array}$ \\
\hline Registro reflexivo & II & PARTICIPANTE, r.r. & $\begin{array}{l}\text { Solicitado aos participantes do curso } \\
\text { depois do término do módulo II. Indicamos } \\
\text { o código - r.p. - e o nome fictício do } \\
\text { participante. }\end{array}$ \\
\hline Atas & II & Ata - GT Escola - data & $\begin{array}{l}\text { Solicitadas aos GT sobre o que aconteceu nos } \\
\text { encontros presenciais. As atas já eram uma } \\
\text { prática dos GT desde o início do Pibid/UFLA/ } \\
\text { Matemática. Indicamos o código - ata -, o GT } \\
\text { Escola (indicado por A, C ou D) e a data em } \\
\text { que foi realizada a aula presencial. }\end{array}$ \\
\hline
\end{tabular}

Fonte: Mendes (2013, p. 103-104).

Realizada essa primeira parte, da pré-análise, partimos para a segunda fase apresentada por Bardin (1977) e Franco (2008).

\section{EXPLORAÇÃO DO MATERIAL}

Nessa fase, o corpus estabelecido deverá ser estudado mais profundamente, com o objetivo de estabelecer as unidades de registro e unidades de contexto. "Os resultados brutos são tratados de maneira a serem significativos (falantes) e válidos” (BARDIN, 1977, p. 101).

$\mathrm{Na}$ verdade, com uma pré-análise bem realizada, essa fase “não é mais do que a administração sistemática das decisões tomadas" (BARDIN, 1977, p. 101).

Assim, partimos para a determinação das unidades de registro. “A Unidade de Registro é a menor parte do conteúdo, cuja ocorrência é registrada de acordo com as categorias levantadas" (FRANCO, 2008, p. 41). Os registros, de acordo com Franco (2008), podem ser de distintos tipos que podem estar inter-relacionados: a palavra, o tema, o personagem, o item.

Escolhemos o tema como nossa "unidade de registro" por ser uma afirmação sobre determinado assunto que envolve "não apenas componentes racionais, mas também ideológicos, afetivos e emocionais" (FRANCO, 2008, p. 43). Segundo Bardin, o tema "é a unidade de 
significação que se liberta naturalmente de um texto analisado segundo certos critérios relativos à teoria que serve de guia à leitura” (1977, p. 105).

Voltamos aos dados, por meio dos procedimentos metodológicos aplicados, os registros orais (entrevistas coletivas e transcrições dos encontros presenciais) e escritos (fóruns de discussão, registros reflexivos, atas), constituídos nos encontros presenciais e não presenciais, e fomos explorá-los. Olhamos para cada um de maneira isolada, buscando as unidades de significação a partir de temas.

Bardin (1977) aponta que, em alguns casos, o uso de computadores pode ser interessante para a análise de conteúdo, como, por exemplo, quando a unidade de registro é a palavra. Em outros casos, a utilização de computadores pode ser ineficaz quando a análise for exploratória ou a unidade de codificação for grande (discurso ou artigo), como foi o nosso caso. Assim, optamos por fazer um trabalho de análise “artesanal”.

Imprimimos as mensagens dos fóruns de discussão, os registros reflexivos, as atas, as entrevistas coletivas e as transcrições dos encontros presenciais que tínhamos. Lemos novamente cada uma das mensagens, buscando congruências e diferenças entre elas. Utilizamos cores diferentes e elaboramos uma legenda. Separamos as mensagens de acordo com alguns temas iniciais que fomos estabelecendo. Recortamos as mensagens e montamos cartazes em papel pardo, como apresentado na Figura 2.

\section{FIGURA 2}

UNIDADES DE REGISTRO - TEMAS INICIAIS

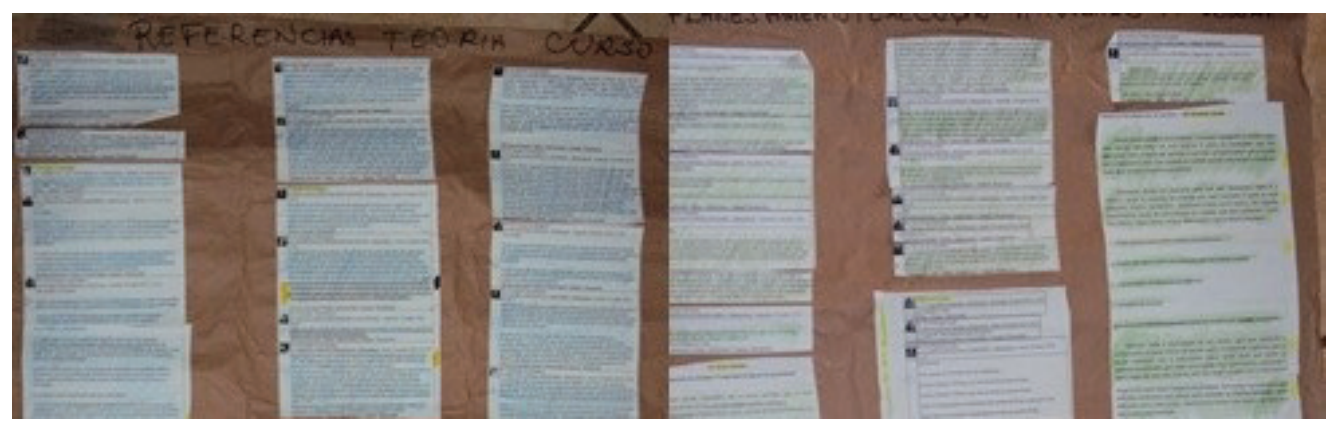

Fonte: Mendes (2013, p. 106).

Nesse processo, inicialmente, encontramos 19 temas, explicitados no Quadro 5, que traz as observações sobre a maneira como os agrupamentos foram realizados a partir dos procedimentos metodológicos aplicados.

Os registros orais (entrevistas coletivas e transcrições dos encontros presenciais) e escritos (fóruns de discussão, registros reflexivos, atas) foram desmembrados de acordo com os temas. Alguns desses temas foram levantados a partir dos fóruns de discussão no Aprender/UFLA. 
QUADRO 5

UNIDADES DE REGISTRO - TEMAS INICIAIS

\begin{tabular}{|c|c|}
\hline TEMAS & OBSERVAÇÕES SOBRE OS AGRUPAMENTOS \\
\hline Experiências com as TIC & $\begin{array}{l}\text { Relatos e discussões sobre experiências anteriores que os participantes } \\
\text { tiveram com a utilização das TIC no processo de ensinar e aprender } \\
\text { Matemática. }\end{array}$ \\
\hline Discussões sobre a Matemática & $\begin{array}{l}\text { Nesse tema agrupamos todas as discussões sobre os conceitos } \\
\text { matemáticos que foram trabalhados nas atividades elaboradas. }\end{array}$ \\
\hline $\begin{array}{l}\text { Planejamento/execução das } \\
\text { atividades }\end{array}$ & $\begin{array}{l}\text { Continha as mensagens que tratavam do planejamento das atividades } \\
\text { para a utilização das TIC no processo de ensinar e aprender Matemática, } \\
\text { desde o processo de criação até as atividades elaboradas, além das } \\
\text { discussões dos participantes sobre o processo. }\end{array}$ \\
\hline $\begin{array}{l}\text { Sentimentos em relação ao uso das } \\
\text { TIC }\end{array}$ & $\begin{array}{l}\text { Sentimentos em relação ao uso das TIC e discussão sobre os bloqueios } \\
\text { que possuíam. }\end{array}$ \\
\hline $\begin{array}{l}\text { Constituição da prática pedagógica } \\
\text { para o uso das TIC }\end{array}$ & $\begin{array}{l}\text { Reflexões mais gerais sobre a importância de uma formação para os } \\
\text { professores para a utilização das TIC. }\end{array}$ \\
\hline Referências ao curso de extensão & $\begin{array}{l}\text { Considerações sobre o Curso de Extensão e sobre como a configuração } \\
\text { do mesmo, com a disponibilização de textos, a exploração de softwares e } \\
\text { o planejamento coletivo de atividades, auxiliou os participantes a refletir } \\
\text { sobre o processo de ensinar e aprender Matemática com a medição das } \\
\text { TIC. }\end{array}$ \\
\hline Considerações sobre o grupo Pibid & $\begin{array}{l}\text { Com as considerações dos participantes a respeito do grupo Pibid. Como } \\
\text { buscaram participar do mesmo e algumas reflexões sobre como o mesmo } \\
\text { pode auxiliá-los em sua formação. }\end{array}$ \\
\hline $\begin{array}{l}\text { Considerações sobre a teoria } \\
\text { estudada }\end{array}$ & Reflexões sobre os textos disponibilizados durante o Curso de Extensão. \\
\hline Reflexões sobre o uso das TIC & $\begin{array}{l}\text { Reflexões sobre a utilização das TIC no processo de ensinar e aprender } \\
\text { Matemática. }\end{array}$ \\
\hline Inclusão/exclusão digital & $\begin{array}{l}\text { Discussões sobre a inclusão e exclusão digital e sua relação com a } \\
\text { inclusão e exclusão social. }\end{array}$ \\
\hline Software livre & Todas as referências aos softwares utilizados no Curso de Extensão. \\
\hline Visões sobre as TIC & $\begin{array}{l}\text { Reflexões individuais dos participantes sobre a visão que tinham sobre } \\
\text { as TIC. }\end{array}$ \\
\hline $\begin{array}{l}\text { Aspectos metodológicos do ensino } \\
\text { da Matemática/prática docente }\end{array}$ & $\begin{array}{l}\text { Reflexões sobre a maneira como as TIC poderiam ser utilizadas no } \\
\text { processo de ensinar e aprender Matemática e sobre a prática docente no } \\
\text { contexto das TIC. }\end{array}$ \\
\hline Burocracia/problemas técnicos & $\begin{array}{l}\text { Comentários sobre as dificuldades para a utilização das TIC como a } \\
\text { burocracia e problemas técnicos enfrentados na escola. }\end{array}$ \\
\hline Imigrante/nativo digital & $\begin{array}{l}\text { Resposta a um teste colocado no Fórum de Discussão sobre como } \\
\text { utilizavam a Internet. }\end{array}$ \\
\hline Políticas públicas e TIC & $\begin{array}{l}\text { Referências à importância das políticas públicas para a formação de } \\
\text { professores para a utilização das TIC. }\end{array}$ \\
\hline Papel/postura do professor & $\begin{array}{l}\text { Referências ao papel e à postura do professor diante das TIC no processo } \\
\text { de ensinar e aprender Matemática. }\end{array}$ \\
\hline Referências ao projeto na escola & $\begin{array}{l}\text { As escolas participantes do grupo Pibid/Matemática estavam realizando } \\
\text { alguns projetos. Todas as mensagens que continham referências } \\
\text { específicas a estes projetos foram agrupadas nesse tema. }\end{array}$ \\
\hline Considerações sobre a escola & Referências às situações das escolas participantes. \\
\hline
\end{tabular}

Fonte: Mendes (2013, p. 106-107).

Depois disso, estabelecemos a unidade de contexto, apontada por Franco (2008) como o "pano de fundo" que fornece significado às unidades de análise. De acordo com Bardin (1977, p. 108), essa pode ser determinada seguindo dois critérios:

O custo e a pertinência. É evidente que uma unidade de contexto alargado, exige uma releitura do meio, mais vasta. Por outro lado, existe uma dimensão óptima, ao nível do sentido: se a unidade de 
Retornamos aos dados, agora buscando as recorrências e não recorrências, procurando o que cada participante havia explicitado em cada um dos procedimentos metodológicos, agora agrupados nos cartazes. Percebemos, nesse momento, que seria possível fazer alguns reagrupamentos, procurando as confluências e as disparidades nos temas e assim pudemos constituir os 12 eixos temáticos apresentados no Quadro 6.

Os eixos temáticos foram compostos pelos temas iniciais, sem re-agrupamentos posteriores, uma vez que não percebemos nenhuma confluência entre eles:

- sentimentos em relação ao uso das TIC;

- planejamento/execução das atividades;

- considerações sobre a teoria estudada;

- burocracia/problemas técnicos;

- experiências com as TIC;

- discussões sobre a Matemática;

- constituição da prática pedagógica para o uso das TIC.

\section{QUADRO 6}

EIXOS TEMÁTICOS

\begin{tabular}{|l|l|}
\hline \multicolumn{1}{|c|}{ EIXOS TEMÁTICOS } & \multicolumn{1}{c|}{ TEMAS INICIAIS } \\
\hline \multirow{2}{*}{ Considerações sobre o grupo Pibid } & Considerações sobre o grupo Pibid \\
\cline { 2 - 2 } & Referências ao projeto na escola \\
\cline { 2 - 2 } & Considerações sobre a escola \\
\hline \multirow{2}{*}{ Referências ao Curso de Extensão } & Referências ao Curso de Extensão \\
\cline { 2 - 2 } & Políticas públicas e TIC \\
\hline \multirow{2}{*}{ Reflexões sobre o uso das TIC } & Inclusão/exclusão digital \\
\cline { 2 - 2 } & Software livre \\
\cline { 2 - 2 } & Reflexões sobre o uso das TIC \\
\cline { 2 - 2 } & Visões sobre as TIC \\
\cline { 2 - 2 } & Imigrante/nativo digital \\
\cline { 2 - 2 } Aspectos metodológicos do ensino da Matemática & Papel/postura do professor \\
\cline { 2 - 2 } & Aspectos metodológicos do ensino da Matemática \\
\hline Sentimentos em relação ao uso das TIC & Prática docente \\
\hline Planejamento/execução das atividades & Sentimentos em relação ao uso das TIC \\
\hline Considerações sobre a teoria estudada & Planejamento/execução das atividades \\
\hline Burocracia/problemas técnicos & Considerações sobre a teoria estudada \\
\hline Experiências com as TIC & Burocracia/problemas técnicos \\
\hline Discussões sobre a Matemática & Experiências com as TIC \\
\hline Constituição da prática pedagógica para o uso das TIC & Discussões sobre a Matemática \\
\hline \multirow{2}{*}{ Fon } & Constituição da prática pedagógica para o uso das TIC \\
\hline
\end{tabular}

Fonte: Mendes (2013, p. 108-109). 
Apresentamos, no Quadro 7, os eixos temáticos referentes aos dados coletados no módulo I, no Quadro 8, aqueles alusivos ao módulo II e, no Quadro 9, os referentes ao Curso de Extensão (módulos I e II). Tais quadros foram elaborados com base naqueles apresentados em Melo (2008).

\section{QUADRO 7}

EIXOS TEMÁTICOS - MÓDULO I

\begin{tabular}{|c|c|c|c|c|c|c|c|c|c|c|c|c|c|c|c|c|c|c|c|c|c|c|c|}
\hline & & & & & & & & & & & ART & $\mathrm{ICIF}$ & $\mathrm{AN}$ & & & & & & & & & & \\
\hline 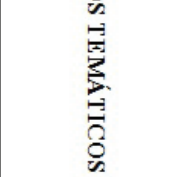 & & $\frac{z}{2}$ & $\begin{array}{l}z \\
z \\
z\end{array}$ & 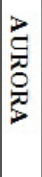 & 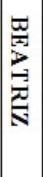 & $\stackrel{\varpi}{5}$ & 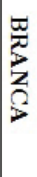 & $\frac{3}{2}$ & $\frac{2}{2}$ & 总 & $\begin{array}{l}\stackrel{\Xi}{\varrho} \\
\underset{\sim}{2}\end{array}$ & $\underset{g}{g}$ & 皇 & $\vec{z}$ & 焉 & 촐 & $\frac{3}{2}$ & $\frac{2}{2}$ & 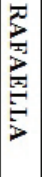 & 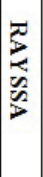 & 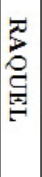 & 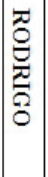 & 苞 \\
\hline Reflexões sobre 0 & 1 & & & & & & & & & & & & & & & & & & & & & & \\
\hline uso das TIC & 2 & & & & & & & & & & & & & & & & & & & & & & \\
\hline Experiências com & 1 & & & & & & & & & & & & & & & & & & & & & & \\
\hline as TIC & 2 & & & & & & & & & & & & & & & & & & & & & & \\
\hline $\begin{array}{l}\text { Sentimentos em } \\
\text { relação ao uso das }\end{array}$ & 1 & & & & & & & & & & & & & & & & & & & & & & \\
\hline TIC & 2 & & & & & & & & & & & & & & & & & & & & & & \\
\hline $\begin{array}{l}\text { Constituição da } \\
\text { prática pedagógica }\end{array}$ & 1 & & & & & & & & & & & & & & & & & & & & & & \\
\hline para o uso das TIC & 2 & & & & & & & & & & & & & & & & & & & & & & \\
\hline Inclusão/Exclusão & 1 & & & & & & & & & & & & & & & & & & & & & & \\
\hline Digital & 2 & & & & & & & & & & & & & & & & & & & & & & \\
\hline Burocracia/ & 1 & & & & & & & & & & & & & & & & & & & & & & \\
\hline $\begin{array}{c}\text { Problemas } \\
\text { Técnicos }\end{array}$ & 2 & & & & & & & & & & & & & & & & & & & & & & \\
\hline $\begin{array}{c}\text { Aspectos } \\
\text { Metodológicos do }\end{array}$ & 1 & & & & & & & & & & & & & & & & & & & & & & \\
\hline $\begin{array}{c}\text { Ensino da } \\
\text { Matemática }\end{array}$ & 2 & & & & & & & & & & & & & & & & & & & & & & \\
\hline Considerações & 1 & & & & & & & & & & & & & & & & & & & & & & \\
\hline $\begin{array}{c}\text { sobre a teoria } \\
\text { estudada }\end{array}$ & 2 & & & & & & & & & & & & & & & & & & & & & & \\
\hline Referências ao & 1 & & & & & & & & & & & & & & & & & & & & & & \\
\hline Curso de Extensã & 2 & & & & & & & & & & & & & & & & & & & & & & \\
\hline $\begin{array}{l}\text { Planejamento/ } \\
\text { Execucão das }\end{array}$ & 1 & & & & & & & & & & & & & & & & & & & & & & \\
\hline Atividades & & & & & & & & & & & & & & & & & & & & & & & \\
\hline
\end{tabular}

Procedimentos metodológicos da pesquisa:

1. Registros escritos.

2. Registros orais.

Fonte: Mendes (2013, p. 110).

Não houve nenhuma mensagem para os eixos temáticos “Considerações sobre o grupo Pibid” e "Discussões sobre a Matemática” no módulo I, pois o registro reflexivo foi feito somente no final do módulo II, quando solicitamos aos participantes que fizessem considerações sobre a participação de cada um deles no Pibid. As discussões sobre os conceitos matemáticos trabalhados foram realizadas em relação à aplicação das atividades planejadas nos encontros presenciais do módulo II. 


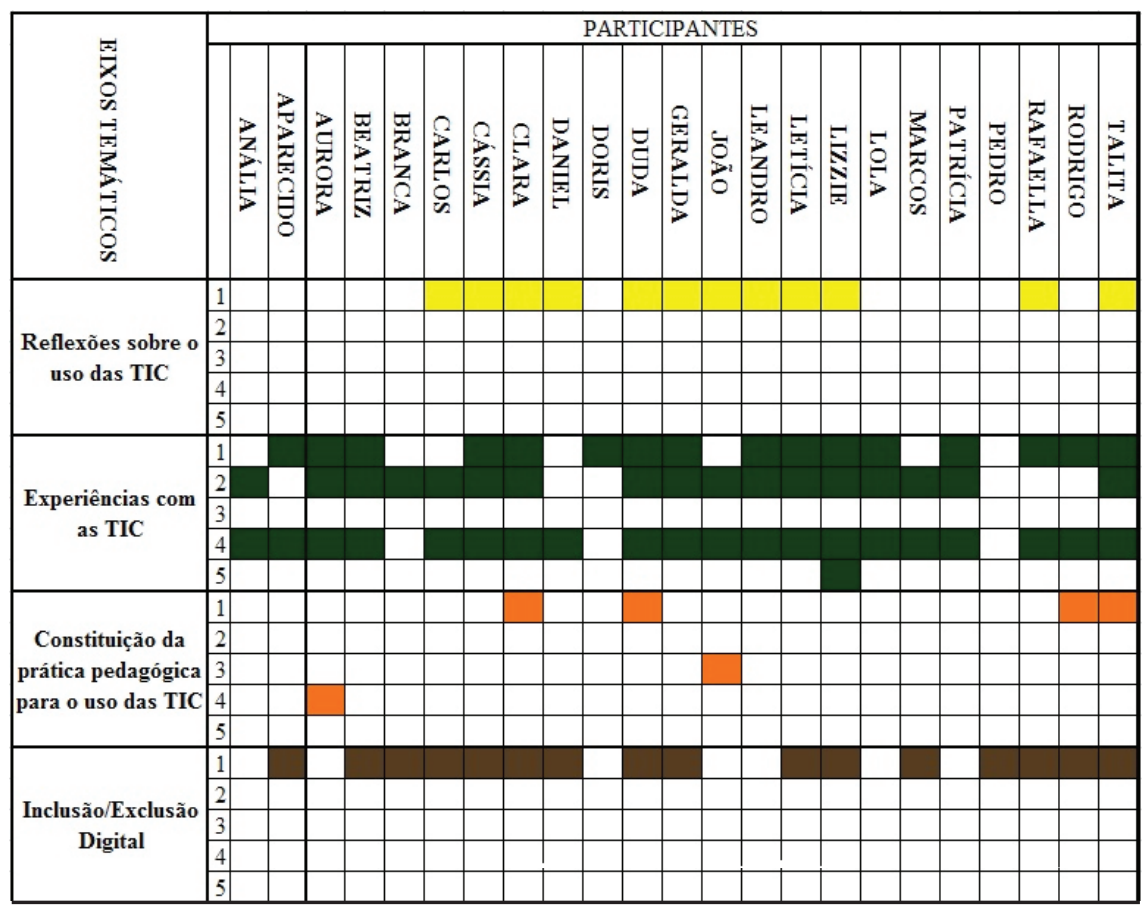

Procedimentos metodológicos da pesquisa:

1. Registros escritos.

2. Registros orais.

3. Registro oral dos encontros presenciais.

4. Registro reflexivo.

5. Atas.

Fonte: Mendes (2013, p. 111).

Analisamos separadamente cada um desses contextos (módulos I e II) e, somente depois, buscamos, a partir do que tinha sido recorrente e excludente em cada um, reorganizar os eixos temáticos, como foi realizado anteriormente com os temas, para estabelecer as categorias de análise, por meio da triangulação dos dados. De acordo com Denzin e Lincoln (2006), a triangulação pode ser vista como uma tentativa de se entender profundamente um fenômeno estudado.

A combinação de várias práticas metodológicas, materiais empíricos, perspectivas de observações em um único estudo é meIhor entendida, então, como uma estratégia que acrescenta rigor, abrangência, complexidade, riqueza e profundidade a qualquer pesquisa. (DENZIN; LINCOLN, 2006, p. 5)

Fizemos a composição dos quadros 7 e 8 e, assim, chegamos à síntese dos procedimentos metodológicos que tínhamos em mãos. 
Após essa etapa, buscamos estabelecer um quadro que marcava a frequência de cada um dos eixos temáticos constituídos. Com um total de 31 participantes, buscamos perceber quando cada um deles fazia alguma menção em alguma mensagem dos eixos temáticos. Tendo em vista que nossa pesquisa caracteriza-se como qualitativa, não realizamos uma contagem do número de mensagens, uma vez que as mesmas apresentavam-se inter-relacionadas. Por exemplo, em um mesmo registro reflexivo apareceram mensagens que estavam contidas em mais de um eixo temático. Porém, pretendíamos mapeá-los, buscando as recorrências e as não recorrências. Assim, montamos o Quadro 9 a partir dos eixos temáticos do Curso de Extensão (módulos I e II) e da recorrência dos instrumentos utilizados, conforme mostra a Tabela 1.

\section{QUADRO 9}

EIXOS TEMÁTICOS - CURSO DE EXTENSÃO (MÓDULOS I E II)

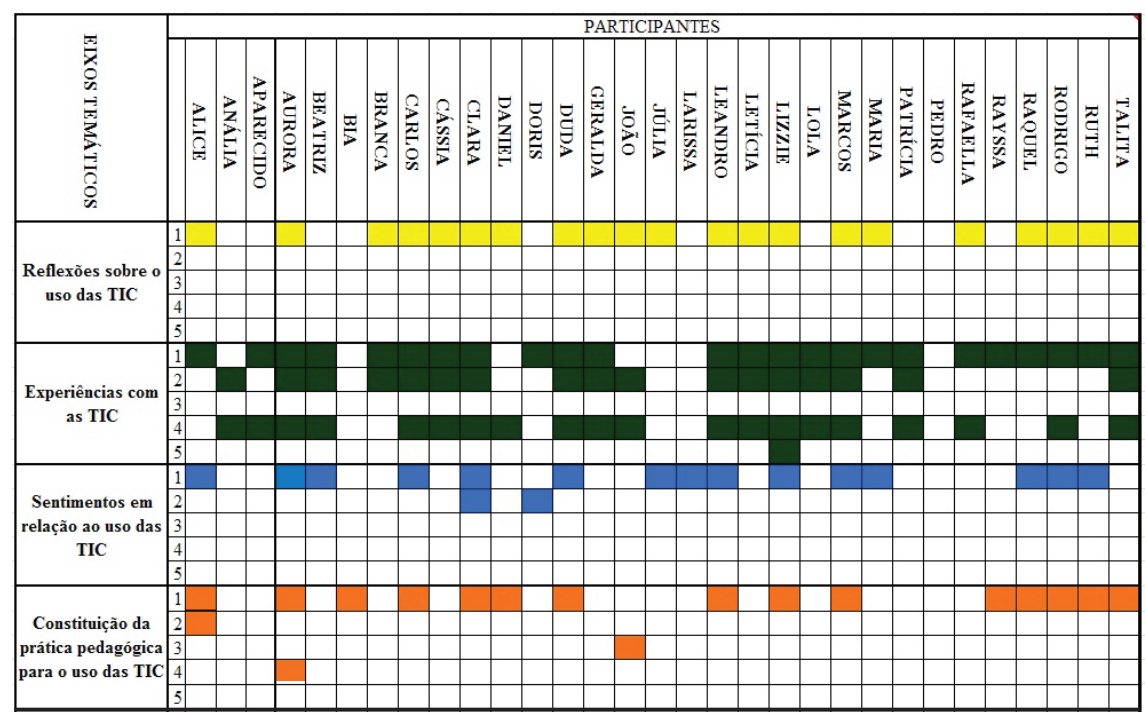

Procedimentos metodológicos da pesquisa:

1. Registros escritos.

2. Registros orais.

3. Registro oral dos encontros presenciais.

4. Registro reflexivo.

5. Atas.

Fonte: Mendes (2013, p. 113). 
TABELA 1

INSTRUMENTOS UTILIZADOS, SEGUNDO EIXOS TEMÁTICOS - RECORRÊNCIAS

\begin{tabular}{|c|c|c|}
\hline EIXOS TEMÁTICOS E INSTRUMENTOS & $\mathrm{N}$ & $\%$ \\
\hline \multicolumn{3}{|c|}{ REFLEXÕES SOBRE O USO DAS TIC } \\
\hline 1. Registros escritos & 21 & 65,63 \\
\hline 2. Registros orais & 0 & 0 \\
\hline 3. Registro oral dos encontros presenciais & 0 & 0 \\
\hline 4. Registro reflexivo & 0 & 0 \\
\hline 5. Atas & 0 & 0 \\
\hline \multicolumn{3}{|c|}{ EXPERIÊNCIAS COM AS TIC } \\
\hline 1. Registros escritos & 24 & 75 \\
\hline 2. Registros orais & 17 & 53,13 \\
\hline 3. Registro oral dos encontros presenciais & 0 & 0 \\
\hline 4. Registro reflexivo & 20 & 62,50 \\
\hline 5. Atas & 1 & 3,13 \\
\hline \multicolumn{3}{|c|}{ SENTIMENTOS EM RELAÇÃO AO USO DAS TIC } \\
\hline 1. Registros escritos & 15 & 46,88 \\
\hline 2. Registros orais & 2 & 6,25 \\
\hline 3. Registro oral dos encontros presenciais & 0 & 0 \\
\hline 4. Registro reflexivo & 0 & 0 \\
\hline 5. Atas & 0 & 0 \\
\hline \multicolumn{3}{|c|}{ CONSTITUIÇÃO DA PRÁTICA PEDAGÓGICA PARA O USO DAS TIC } \\
\hline 1. Registros escritos & 15 & 46,88 \\
\hline 2. Registros orais & 1 & 3,13 \\
\hline 3. Registro oral dos encontros presenciais & 1 & 3,13 \\
\hline 4. Registro reflexivo & 1 & 3,13 \\
\hline 5. Atas & 0 & 0 \\
\hline
\end{tabular}

\begin{tabular}{|c|c|c|}
\hline 1. Registros escritos & 25 & 78,13 \\
\hline 2. Registros orais & 0 & 0 \\
\hline 3. Registro oral dos encontros presenciais & 0 & 0 \\
\hline 4. Registro reflexivo & 0 & 0 \\
\hline 5. Atas & 0 & 0 \\
\hline
\end{tabular}

\begin{tabular}{lll|c} 
5. Atas & 0 & 0 \\
\hline
\end{tabular}

BUROCRACIA/PROBLEMAS TÉCNICOS

1. Registros escritos

2. Registros orais

3. Registro oral dos encontros presenciais

\begin{tabular}{l|l|c}
\hline 4. Registro reflexivo & 3 & 9,38 \\
\hline 5. Atas & 1 & 3,13 \\
\hline
\end{tabular}

\begin{tabular}{cccc} 
5. Atas & 1 & 3,13 \\
\hline ASPECTOS METODOLÓGICOS DO ENSINO & & \\
DA MATEMÁTICA
\end{tabular}

\begin{tabular}{l|c|c}
\hline 1. Registros escritos & 17 & 53,13 \\
\hline 2. Registros orais & 3 & 9,38 \\
\hline 3. Registro oral dos encontros presenciais & 0 & 0 \\
\hline 4. Registro reflexivo & 7 & 21,88 \\
\hline 5. Atas & 0 & 0
\end{tabular}

\begin{tabular}{|c|c|c|}
\hline 1. Registros escritos & 24 & 75,00 \\
\hline 2. Registros orais & 4 & 12,50 \\
\hline 3. Registro oral dos encontros presenciais & 0 & 0 \\
\hline 4. Registro reflexivo & 11 & 34,38 \\
\hline 5. Atas & 0 & 0 \\
\hline
\end{tabular}




\begin{tabular}{|c|c|c|}
\hline EIXOS TEMÁTICOS E INSTRUMENTOS & $\mathrm{N}$ & $\%$ \\
\hline \multicolumn{3}{|c|}{ REFERÊNCIAS AO CURSO } \\
\hline 1. Registros escritos & 3 & 9,38 \\
\hline 2. Registros orais & 21 & 65,63 \\
\hline 3. Registro oral dos encontros presenciais & 0 & 0 \\
\hline 4. Registro reflexivo & 14 & 43,75 \\
\hline 5. Atas & 0 & 0 \\
\hline \multicolumn{3}{|c|}{ DISCUSSÕES SOBRE A MATEMÁTICA } \\
\hline 1. Registros escritos & 11 & 34,38 \\
\hline 2. Registros orais & 0 & 0 \\
\hline 3. Registro oral dos encontros presenciais & 0 & 0 \\
\hline 4. Registro reflexivo & 0 & 0 \\
\hline 5. Atas & 0 & 0 \\
\hline \multicolumn{3}{|c|}{ CONSIDERAÇÕES SOBRE O PIBID } \\
\hline 1. Registros escritos & 0 & 0 \\
\hline 2. Registros orais & 2 & 6,25 \\
\hline 3. Registro oral dos encontros presenciais & 0 & 0 \\
\hline 4. Registro reflexivo & 21 & 65,63 \\
\hline 5. Atas & 0 & 0 \\
\hline \multicolumn{3}{|c|}{ PLANEJAMENTO/EXECUÇÃO DAS ATIVIDADES } \\
\hline 1. Registros escritos & 17 & 53,13 \\
\hline 2. Registros orais & 9 & 28,13 \\
\hline 3. Registro oral dos encontros presenciais & 0 & 0 \\
\hline 4. Registro reflexivo & 10 & 31,25 \\
\hline 5. Atas & 2 & 6,25 \\
\hline
\end{tabular}

Fonte: Mendes (2013, p. 114-116).

Apresentamos no próximo item a formação das categorias de análise.

\section{TRATAMENTO DOS RESULTADOS, A INFERÊNCIA E A INTERPRETAÇÃO}

Nessa fase, os dados coletados foram tratados de maneira que pudessem ser significativos fazendo uso, em nosso caso, de quadros, estabelecendo, a partir dos 12 eixos temáticos e da tabela de recorrências e as diferenças, as categorias de análise da pesquisa, que segundo Bardin (1977, p. 117) emergem por meio de uma "operação de classificação de elementos constitutivos de um conjunto, por diferenciação e, seguidamente, por reagrupamento segundo o género (analogia), com os critérios previamente definidos".

Esse trabalho minucioso foi importante, pois permitiu ficarmos imbuídas dos dados, uma vez que, a cada passo, fazíamos muitas leituras dos mesmos, o que nos possibilitou ir percebendo as minúcias que poderiam ter ficado de lado, se não fosse esse processo de idas e vindas. Assim, fomos buscar o estabelecimento das categorias, ponto crucial para nossa análise, mirando sempre na questão de investigação, no objetivo da pesquisa e na teoria que seria nosso fio condutor, o conceito de CoP e Identidade (WENGER, 1998). 
Seguimos os princípios apresentados por Bardin (1977) e Franco (2008):

- exclusão mútua - "Esta condição estipula que cada elemento não pode existir em mais de uma divisão” (BARDIN, 1977, p. 120). Procuramos organizar nossos dados de maneira que um mesmo dado não pudesse ser incluso em mais de uma categoria;

- homogeneidade - “O princípio de exclusão mútua depende da homogeneidade das categorias. Um único princípio de classificação deve governar a sua organização" (BARDIN, 1977, p. 120). Além de buscarmos que nossas categorias fossem abrangentes de modo que permitissem a inclusão de todos os dados, nos preocupamos que as mesmas fossem homogêneas, ou seja, estivessem de acordo com os temas estabelecidos nas etapas anteriores da análise;

- pertinência - “uma categoria é considerada pertinente quando está adaptada ao material de análise escolhido, e quando pertence ao quadro teórico definido" (BARDIN, 1977, p. 120). No nosso caso, entendemos que as categorias obedecem a esse critério pelas idas e vindas que fizemos em relação à questão de investigação, ao objetivo e à teoria durante todo o processo de estabelecimento das mesmas;

- objetividade e a fidelidade - "As diferentes partes de um mesmo material, ao qual se aplica a mesma grelha categorial, devem ser codificadas da mesma maneira, mesmo quando submetida a várias análises” (BARDIN, 1977, p. 120). Ao propor as categorias, esperávamos que as mesmas fossem objetivas, ou seja, que pudessem ser aplicadas ao longo de toda a análise. Por isso, realizamos uma descrição detalhada e clara de como chegamos às categorias estabelecidas, para que outros pesquisadores pudessem chegar a resultados semelhantes utilizando os mesmos procedimentos metodológicos, garantindo sua objetividade e fidedignidade;

- produtividade - "Um conjunto de categorias é produtivo se fornece resultados férteis: férteis em índices de inferências, em hipóteses novas e em dados exactos" (BARDIN, 1977, p. 120-121).

O Quadro 10 apresenta as categorias de análise estabelecidas. 


\begin{tabular}{|c|c|}
\hline CATEGORIAS DE ANÁLISE & EIXOS TEMÁTICOS \\
\hline \multirow{5}{*}{$\begin{array}{l}\text { Reflexões teóricas e metodológicas } \\
\text { produzidas no grupo/comunidade sobre o } \\
\text { uso das TIC }\end{array}$} & Considerações sobre a teoria estudada \\
\hline & Reflexões sobre o uso das TIC \\
\hline & $\begin{array}{l}\text { Aspectos metodológicos do ensino da } \\
\text { Matemática }\end{array}$ \\
\hline & Inclusão/exclusão digital \\
\hline & Burocracia/problemas técnicos \\
\hline \multirow{4}{*}{$\begin{array}{l}\text { Desafios do uso das TIC nas escolas do } \\
\text { grupo/comunidade Pibid }\end{array}$} & Experiências com as TIC \\
\hline & Discussões sobre a Matemática \\
\hline & Planejamento/execução das atividades \\
\hline & Sentimentos em relação ao uso das TIC \\
\hline \multirow[t]{3}{*}{$\begin{array}{l}\text { Constituição da prática pedagógica para o } \\
\text { uso das TIC }\end{array}$} & $\begin{array}{l}\text { Constituição da prática pedagógica para o } \\
\text { uso das TIC }\end{array}$ \\
\hline & Referências ao Curso de Extensão \\
\hline & Considerações sobre o grupo Pibid \\
\hline
\end{tabular}

Fonte: Mendes (2013, p. 118).

A partir desse processo, que decidimos apresentar minuciosamente, mostramos a descrição e a análise dos dados constituídos nos módulos I e II.

A análise se baseou na Teoria Social da Aprendizagem apresentada por Wenger (1998), mais especificamente no conceito de Comunidades de Prática, teoria que fundamentava nossa pesquisa. Buscamos perceber a negociação de significados que ocorreu entre os participantes, professores da Universidade, professores em serviço da rede pública da cidade de Lavras e os alunos da licenciatura em Matemática da UFLA durante o Curso de Extensão e se os componentes "significado, prática e comunidade”, que caracterizam a participação social como um processo de aprender e conhecer, perpassaram a investigação, enquanto os participantes planejaram, experimentaram e vivenciaram a complexidade que é ensinar matemática com a mediação da tecnologia.

Assim, a Matemática, a Tecnologia da Informação e Comunicação e a Prática Pedagógica formaram o contexto para a construção da negociação de significados sobre os conceitos matemáticos e pedagógicos do grupo/comunidade de professores.

Nossa intenção nesse artigo foi mostrar o percurso metodológico para a constituição e análise dos dados, o que se mostra importante para dar qualidade à pesquisa realizada.

Ainda sobre a pesquisa qualitativa, a "preocupação com o processo é muito maior do que com o produto" (LÜDKE; ANDRÉ, 1986, p. 12). O significado que as pessoas conferem às coisas e à sua vida $\mathrm{e}$ suas perspectivas se mostram essencial para o pesquisador qualitativo, ou seja, existe uma relação entre o participante da pesquisa e o objeto de estudo (BOGDAN; BIKLEN, 1994). Nesse sentido, durante o Curso de Extensão realizado, procuramos identificar como os participantes 
negociavam o significado, como as expectativas se traduziram nas interações realizadas.

Assim, os participantes integraram o processo do conhecimento e interpretaram os acontecimentos, dando um significado próprio em que o objeto não foi um fenômeno inerte ou neutro, mas estava imbuído de significados e relações que os participantes criaram em suas ações (CHIZZOTTI, 1991, p. 79). Nessa pesquisa nos preocupamos com as percepções, com os significados que esses atribuíram à prática, considerando a utilização de Tecnologia da Informação e Comunicação - TIC - nos Encontros de Matemática. Nessa perspectiva, tornarmo-nos descobridoras do significado e das relações que se ocultaram nas estruturas sociais, muitas vezes sentida por meio das ferramentas de comunicações e dinâmica metodológica dos encontros no Grupo (CHIZZOTTI, 1991, p. 80).

\section{REFERÊNCIAS}

BARDIN, Laurence. Análise de conteúdo. Lisboa: Edições 70, 1977.

BAUER, Martin W.; GASKELL, Georgs (Org.). Pesquisa qualitativa com texto, imagem e som: um manual prático. Petrópolis, RJ: Vozes, 2012.

BOGDAN, Robert; BIKLEN, Sari. Investigação qualitativa em educação. Portugal: Porto, 1994.

CHIZZOTTI, Antonio. Pesquisa em ciências humanas e sociais. São Paulo: Cortez, 1991.

DENZIN, Norman K.; LINCOLN, Yonna S. O planejamento da pesquisa qualitativa: teorias e abordagens. Tradução de Sandra Regina Netz. Porto Alegre: Artmed, 2006.

FLICK, Uwe. Uma introdução à pesquisa qualitativa. São Paulo: Bookman, 2004.

FRANCO, Maria Laura Puglisi Barbosa. Análise de conteúdo. 3. ed. Brasília: Líber Livro, 2008.

HANNA, Evelyn. Teachers' discourse community: what it reveals about knowledge of teaching mathematics. 2007. Dissertation (Doctor of Education) - The Graduate School of Education Rutgers, The State University of New Jersey, New Jersey, 2007.

KOCH, Ingedore G. V. A inter-ação pela linguagem. São Paulo: Contexto, 2003.

LÜDKE, Menga; ANDRÉ, Marli E. D. A. Pesquisa em educação: abordagens qualitativas. São Paulo: EPU, 1986.

MELO, Maria José Medeiros Dantas de. Olhares sobre a formação do professor de Matemática. Imagem da profissão e escrita de si. 2008. 322 f. Tese (Doutorado em Educação) - Centro de Ciências Sociais Aplicadas, Universidade Federal do Rio Grande do Norte, Natal, 2008.

MENDES, Rosana Maria. A formação do professor que ensina matemática, as tecnologias de informação e comunicação e as comunidades de prática: uma relação possível. 2013. 285 f. Tese (Doutorado em Educação Matemática) - Instituto de Geociências e Ciências Exatas, Universidade Estadual Paulista “Júlio de Mesquita Filho”, Rio Claro, 2013.

WENGER, Etienne. Comunidades de práctica: aprendizaje, significado e identidad. Barcelona: Paidós, 1998. 
ROSANA GIARETTA SGUERRA MISKULIN

Universidade Estadual Paulista "Júlio de Mesquita Filho" - Unesp -, Rio Claro, São Paulo, Brasil

misk@rc.unesp.br 